\title{
Divergence and ranking of taxa across the kingdoms Animalia, Fungi and Plantae
}

\author{
Samarakoon $\mathrm{MC}^{1,2,3}$, Hyde KD ${ }^{1,3}$, Promputtha $\mathrm{I}^{2}$, Ariyawansa $\mathrm{HA}^{4}$, Hongsanan \\ $\mathbf{S}^{1^{*}}$ \\ ${ }^{1}$ Center of Excellence in Fungal Research, Mae Fah Luang University, Chiang Rai 57100, Thailand \\ ${ }^{2}$ Department of Biology, Faculty of Science, Chiang Mai University, Chiang Mai 50200, Thailand \\ ${ }^{3}$ Key Laboratory for Plant Diversity and Biogeography of East Asia, Kunming Institute of Botany, Chinese Academy of \\ Sciences, 132 Lanhei Road, Kunming 650201, China \\ ${ }^{4}$ Guizhou Academy of Sciences, Guiyang, 550009, Guizhou Province, China
}

Samarakoon MC, Hyde KD, Promputtha I, Ariyawansa HA, Hongsanan S. 2016 - Divergence and ranking of taxa across the kingdoms Animalia, Fungi and Plantae. Mycosphere 7(11), 1678-1689, Doi 10.5943/mycosphere/7/11/5

\begin{abstract}
In science, species are grouped and ranked in kingdoms, phyla, classes, orders, families and genera and several other intermediate taxa, in a taxonomic hierarchy. However, the ranking of phyla, classes, orders and families across kingdoms is not linked and there is unlikely to be any correlation between these ranks in animals, fungi or plants. In a few recent studies, divergence times have been used to develop more natural groupings within ranks and it has been suggested that divergence times should be used as a universal criterion in high level ranking. It would therefore be desirable to develop more stable and standardized grouping of taxa in phyla, classes, orders and families across the kingdoms using divergence times. However, is this feasible? The origins of the kingdoms have been well-studied, however a comparison of the earliest divergence of major taxa (phyla, classes, orders, and families) across these kingdoms is lacking. We therefore considered that it would be of interest to look at ranking of groups across three kingdoms, Animalia, Fungi and Plantae. Are the ranking in these kingdoms comparable or has one or more kingdoms been more liberal in splitting taxa at the higher levels (e.g phyla, classes, orders, families)? We used paleobiological information from early diverged groups among the kingdoms Animalia, Fungi and Plantae corresponding to the geological time scale for comparisons. As a general rule, we found that groups of Animalia classified as phyla, classes, orders and families, diverged earlier as compared to those of the kingdoms Fungi and Plantae. This suggests that animal taxonomists have been more liberal when splitting ranks at the phylum, class and order levels, while at the family level the ranking across kingdoms is comparable. The common trend of evolutionary events could therefore be applied for re-ranking of some groups, especially at the generic and perhaps family levels. However, it would appear an impossible task to standardize higher level rankings across the kingdoms, as there would need to be huge, and probably unacceptable changes. Basically, the mycologists and botanists would need to split much more at the phylum, class and order levels, while the zoologists would need to combine many of their phyla, classes and orders. The data however, suggests that fungal and plant taxonomists could be more liberal when considering new families, orders, classes and phyla in the future.
\end{abstract}


Key words - eukaryotic kingdoms - re-ranking - species richness - taxonomic classification

\section{Introduction}

Living organisms comprise seven kingdoms (Ruggiero et al. 2015). The kingdoms Archaea (Archaebacteria) and Bacteria (Eubacteria) are classified in the super kingdom Prokaryota (Ruggiero et al. 2015). The kingdoms Animalia, Chromista, Fungi, Plantae and Protozoa are classified in the super kingdom Eukaryota (Ruggiero et al. 2015). There are two subkingdoms and 34 phyla within the kingdom Animalia and they are taxonomically confused (Ruggiero et al. 2015). The kingdom Fungi has been divided into the phyla Ascomycota and Basidiomycota (subkingdom Dikarya; James et al. 2006), and the phyla Chytridiomycota, Glomeromycota and Zygomycota (Ruggiero et al. 2015) based on morphology and phylogeny. The kingdom Plantae (Archaeplastida) has been ranked in various ways comprising lower and higher plants within the same kingdom (Ruggiero et al. 2015). According to a recent classification, the kingdom Plantae is divided into the subkingdoms Biliphyta and Viridiplantae (Burki 2014, Ruggiero et al. 2015). Table 1 summarizes the number of phyla, classes and orders among the kingdoms Animalia, Fungi and Plantae (Ruggiero et al. 2015). Interestingly there is a higher number of phyla, classes and orders within the kingdom Animalia, as compared to the other two kingdoms. This might suggest that taxonomists studying Animalia have been liberal in ranking at these levels, while the mycologists and botanists have been far more conservative.

Table 1. Current number of the taxa among the kingdoms Animalia, Fungi and Plantae (Ruggiero et al. 2015).

\begin{tabular}{cccc}
\hline \multirow{2}{*}{ Kingdom } & \multicolumn{3}{c}{ No. of Taxa } \\
\cline { 2 - 4 } & Phyla & Classes & Orders \\
\hline Animalia & 34 & $100(96+4)^{*}$ & $598(590+8)^{*}$ \\
Fungi & 5 & $41(34+7)^{*}$ & 147 \\
Plantae & 8 & 42 & $211(209+2)^{*}$ \\
\hline
\end{tabular}

*Total number of taxa (named taxa + taxa without names)

\section{Divergence times, paleobiological studies and ranking of taxa}

Molecular dating is rapidly developing into one of the most exciting applications in phylogenetic systematics (Bromham \& Penny 2003, Kemp 2005, Taylor \& Berbee 2006). Molecular timescales provide insights into the history of organisms and are valuable for predicting evolution in the case of organisms with incomplete, or lack of fossil records (Bromham \& Penny 2003). A combination of geological and molecular information, i.e. paleobiology or geobiology, with appropriate selection of methods, with representative fossil data, provide reliable divergence times for organisms (Guicking et al. 2006, Eme et al. 2014, Magallón et al. 2015).

In taxonomy, species are grouped and ranked in kingdoms, phyla, classes, orders, families, genera and several other intermediate taxa. Authors have suggested the use of divergence times as universal criteria for ranking taxa, or to construct a natural grouping of the organisms within ranks (Woese et al. 1990, Avise \& Johns 1999, Li et al. 2005, Lücking et al. 2009, Prieto \& Wedin 2013, Talavera et al. 2013, Zhao et al. 2016, Hongsanan et al. 2016).

Molecular timescales are widely used in animals, fungi and plants to determine the occurrence of evolutionary events (Wang et al. 1999, Mitchell-Olds \& Bergelson 2000, Bromham \& Penny 2003, Li et al. 2015). The purpose of the present study is to examine the correlation of divergence times of taxa (phyla, classes, orders and families) across the kingdoms Animalia, Fungi and Plantae. The common geological periods are considered based on the early divergences estimated by using available paleobiological information from previous studies (Zhao et al. 2016, Hongsanan et al. 2016). This is mainly to establish the common early divergence times for the taxonomic groups. The aim of this paper is to establish if there are any common trends in the ranking of phyla, classes, orders, families and genera, across the kingdoms Animalia, Fungi and 
Plantae, or whether it is random. This will be of considerable interest when considering standardizing the ranking of taxa across the kingdoms based on divergence times.

\section{Origin and early divergences of organisms grouped as phyla among the kingdoms Animalia, Fungi and Plantae (Table 2)}

During the Paleoproterozoic-Mesoproterozoic (2500-1000 Mya), the kingdoms Animalia, Fungi and Plantae shared common characters with rapid subsequent divergences (Walker et al. 2012, Eme et al. 2014). The kingdoms Animalia and Fungi diverged during the Mesoproterozoic (1600-1000 Mya) from the super group 'Opisthokonta' (metazoans, fungi and some heterotrophic Protists; Hedges et al. 2004, Adl et al. 2005, 2012, Cavalier-Smith 2010, 2014, Burki 2014). The divergence of the plant lineages occurred around 1379 Mya during the Mesoproterozoic (16001000 Mya) from a common eukaryotic ancestor (Bhattacharya et al. 2009).

The earliest groups within the kingdom Animalia, the sponges, hydroids, jellyfish, anemones, corals and comb jellies (phylum Cnidaria) diverged during the Neoproterozoic era (1000-541 Mya, Müller 2001, Müller et al. 2003, Philippe et al. 2009, Park et al. 2012, Jékely et al. 2015). The arthropods (phylum Arthropoda), horseshoe worms (phylum Phoronida), velvet worms (phylum Onychophora), marine deuterostomes, sea stars, sea urchins, sand dollars, sea cucumbers and sea lilies (phylum Echinodermata) diverged in the latter part of the Neoproterozoic era (635-541Mya, Table 2, Rehm et al. 2011, Sperling et al. 2011, Li 2016).

The paleobiological information suggests that the divergence of the phylum Chytridiomycota occurred before the divergence of terrestrial plants, during the Mesoproterozoic era (1242 Mya, Berbee \& Taylor 2001, Padovan et al. 2005, Torruella et al. 2012). The common divergence period for the phyla Ascomycota, Basidiomycota and Glomeromycota occurred mainly in the Neoproterozoic to Early Paleozoic (1000-485Mya), parallel to the divergences of terrestrial animals (Schüßler et al. 2001, Berney \& Pawlowski 2006, Lücking et al. 2009, Beimforde et al. 2014; see Table 2).

The early divergences of red algae (phylum Rhodophyta) and freshwater microscopic algae (phylum Glaucophyta) in the kingdom Plantae, occurred during the Mesoproterozoic (1600-1000 Mya, Zimmer et al. 2007, Nozaki et al. 2009). Most of the terrestrial groups, the mosses (phylum Bryophyta), liverworts (phylum Marchanatiophyta) and vascular plants (phylum Tracheophyta) within the kingdom Plantae have diverged during the Early Paleozoic (419-541 Mya, Zimmer et al. 2007, Clarke et al. 2011, Cooper et al. 2012; see Table 2).

The summarized early divergences of taxonomic phyla within the kingdoms Animalia (blue), Fungi (orange) and Plantae (green) are shown in Table 2 and Fig. 1. The selection of taxa given in the Table 2 is based on recent studies combining fossil and biological data, and divergence time selection being from early diverged groups. Priority was given to studies focusing on specific organism groups than general studies. It was assumed; that such studies have estimated reliable divergence times using representative biological data and calibrations. However, estimated divergence times from general studies were also used in some cases due the lack of data.

The animal phyla groups show a common divergence during the Neoproterozoic (1000-541 Mya) in the Precambrian. Peterson et al. (2004) and Qun et al. (2007) suggested that most animalian phyla diverged during the Early Paleozoic (before 540 Mya), while Knoll (2014) suggested that the extensive diversification of the eukaryotes occurred during the Neoproterozoic (1000-541 Mya). Most of the early divergences in the phylum Fungi occurred during the Neoproterozoic to Early Paleozoic (1000-485 Mya), while the earliest divergences were during the Mesoproterozoic (1600-1000 Mya). The Chytridiomycota divergence occurred earlier than the divergences of most other fungal groups. However, the basal relationships of the polyphyletic lower fungi, Chytridiomycota and Zygomycota are still unresolved (Tanabe et al. 2005, Kirk et al. 2008). The early divergences of plant groups occurred during the Mesoproterozoic (1600-1000 Mya) and most plant phyla diverged during the Paleozoic (541-252 Mya). Parfrey et al. (2011) suggested that the divergence of red algae and green algae occurred during the Mesoproterozoic and Neoproterozoic. This may suggest that there are two common trends in plant group 
divergences. The overall trend is that the Chytridiomycota (early fungi) and Rhodophyta (early plants) evolved earliest follow by Cnidaria (early animals). This was followed by various phyla of Animalia and Fungi and then Plantae. The animal and fungal phyla are generally older than the plant phyla. This may be problematic, as the animal and fungal evolution relied on the plants and therefore the plant phyla should be older.

Table 2. Synopsis of the early diverged groups classified as phyla among the kingdoms Animalia, Fungi and Plantae from recent studies. The 95\% confident intervals are given in brackets.

\begin{tabular}{llll}
\hline \multicolumn{1}{c}{ Phyla } & \multicolumn{1}{c}{$\begin{array}{c}\text { Divergence time estimates } \\
(\text { Mya) }\end{array}$} & \multicolumn{1}{c}{ Geological era } & \multicolumn{1}{c}{ References } \\
\hline Cnidaria & $736(819-686)$ & Neoproterozoic & Park et al. 2012 \\
Arthropoda & $\sim 600$ & Neoproterozoic & Rehm et al. 2011 \\
Onychophora & $589(607-573)$ & Neoproterozoic & Rehm et al. 2011 \\
Echinodermata & 545 & Neoproterozoic & Li 2016 \\
Chytridiomycota & $1241.99(1406.97-1152.70)$ & Mesoproterozoic & Padovan et al. 2005 \\
Ascomycota & $642(859-504)$ & Neoproterozoic-Paleozoic & Beimforde et al. 2014 \\
Glomeromycota & $\sim 720-600$ & Neoproterozoic & Lücking et al. 2009 \\
Basidiomycota & $521(766-452)$ & Neoproterozoic-Paleozoic & Garnica et al. 2016 \\
Rhodophyta & $1142(1309-975)$ & Mesoproterozoic-Neoproterozoic & Zimmer et al. 2007 \\
Bryophyta & $496(580-412)$ & Neoproterozoic-Paleozoic & Zimmer et al. 2007 \\
Marchantiophyta & $484(509-452)$ & Paleozoic & Cooper et al. 2012 \\
Tracheophyta & $446(456-425)$ & Paleozoic & Clarke et al. 2011 \\
\hline
\end{tabular}

\section{Early divergences of organisms grouped as classes among the kingdoms (Table 3)}

The divergences of hydra, freshwater jellies (class Hydrozoa), true jellies (class Scyphozoa), flower animals (class Anthozoa) and arachnids (class Arachnida) occurred during the Late Neoproterozoic (850-541 Mya, Park et al. 2012). Most other animalian classes (eg. Melocostraca, Insecta) diverged and diversified during the Paleozoic era (541-252 Mya, Regier et al. 2004, Sanders \& Lee 2010).

Among the fungi, the highly diversified and species rich Ascomycota diverged into several classes (e.g. class Dothideomycetes, Orbiliomycetes, Pezizomycetes, Sordariomycetes) mainly during the Paleozoic (541-252 Mya, Kirk et al. 2008, Gueidan et al. 2011, Prieto \& Wedin 2013, Beimforde et al. 2014). Among the Basidiomycota, the divergences of the classes might also have taken place during the Paleozoic (see Fig. 1).

The phylum Rhodophyta diverged into early classes Florideophyceae and Bangiophyceae during the Neoproterozoic (1000-541 Mya, Yang et al. 2016). The divergences of several other plant groups known as classes, belongs to non-vascular (classes Haplomitriopsida, Jungermanniopsida, and Marchantiopsida) and vascular (class Cycadopsida) occurred during the Paleozoic (359-299 Mya, see the Table 3 and Fig. 1; Zimmer et al. 2007, Cooper et al. 2012, Condamine et al. 2015, Magallón et al. 2015, Villarreal et al. 2016).

Most animalian groups known as classes diverged during the Neoproterozoic (1000-541 Mya) to Early Paleozoic (541-419 Mya). This agrees with Peterson et al. (2004) with the divergence of animalian phyla and classes being prominent during the Neoproterozoic to Early Paleozoic. The divergences of the fungal and plant groups classified as classes mostly occurred during the Early and Late Paleozoic (541-252 Mya).

\section{Early divergences of organisms grouped as orders among the kingdoms (Table 4)}

Horseshoe crabs (order Xiphosura), shells (order Terebratulida), crayfish, crabs, lobsters, prawns, shrimps (order Decapoda), stony corals, hard corals (order Scleractinia), beetles and weevils (order Coleoptera) diverged mainly during the Paleozoic (541-252 Mya) towards the Late Paleozoic-Early Mesozoic boundary (around 252 Mya, Rehm et al. 2011, Bracken et al. 2010, Sperling et al. 2011, Park et al. 2012, McKenna et al. 2015; see Table 4 and Fig. 1). 
The highly diversified classes of Ascomycota and Basidiomycota comprise mycorrhizal, saprotrophic, parasitic, lichenized and non-lichenized fungi groups (e.g. Sebacinales, Ostropales, Mycocaliciales, Boletales, Pyrenulales) which have diverged during the Mesozoic (252-66 Mya, Prieto \& Wedin 2013, Garnica et al. 2016, Riess et al. 2016, Sánchez-Ramírez et al. 2015; see Table 4 and Fig. 1).

Table 3. Synopsis of early diverged groups classified as classes among the kingdoms Animalia, Fungi and Plantae from recent studies. The 95\% confident intervals are given in brackets.

\begin{tabular}{llll}
\hline \multicolumn{1}{c}{ Class } & \multicolumn{1}{c}{$\begin{array}{c}\text { Divergence time estimates } \\
\text { (Mya) }\end{array}$} & \multicolumn{1}{c}{ Geological era } & References \\
\hline Hydrozoa & $607(670-571)$ & Neoproterozoic & Park et al. 2012 \\
Anthozoa & $601(684-544)$ & Neoproterozoic & Park et al. 2012 \\
Arachnida & $545.2(631.1-475.9)$ & Neoproterozoic-Paleozoic & Sanders \& Lee 2010 \\
Insecta & $389.9(527.4-266.9)$ & Paleozoic & Sanders \& Lee 2010 \\
Pezizomycetes & $458(583-400)$ & Neoproterozoic-Paleozoic & Beimforde et al. 2014 \\
Orbiliomycetes & $430(554-353)$ & Neoproterozoic-Paleozoic & Beimforde et al. 2014 \\
Dothideomycetes & $338(394-284)$ & Paleozoic & Gueidan et al. 2011 \\
Sordariomycetes & $260(339-207)$ & Paleozoic-Mesozoic & Beimforde et al. 2014 \\
Florideophyceae & $943(1049-817)$ & Mesoproterozoic-Neoproterozoic & Yang et al. 2016 \\
Haplomitriopsida & $414(469-352)$ & Paleozoic & Cooper et al. 2012 \\
Jungermanniopsida & $390(425-353)$ & Paleozoic & Cooper et al. 2012 \\
Cycadopsida & $274.5(332.4-235)$ & Paleozoic-Mesozoic & Condamine et al. 2015 \\
\hline
\end{tabular}

The early divergences of plant groups placed in orders (e.g. Ceramiales) occurred during the Late Paleozoic (395-284 Mya, Yang et al. 2016). Liverworts (e.g. order Marchantiales, Metzgeriales, Pelliales) and aquatic flowering plants, trees and shrubs (e.g. order Magnoliales, Nymphaeales, Sphaerocarpales) diverged during the Late Paleozoic to Mesozoic (up to 66 Mya) or Jurassic-Cretaceous (201-66 Mya, Cooper et al. 2012, Villarreal et al. 2016, Massoni 2014, Bell et al. 2005, Magallón et al. 2015; see Table 4 and Fig. 1).

Table 4. Synopsis of early diverged groups classified as orders among the kingdoms Animalia, Fungi and Plantae from recent studies. The 95\% confident intervals are given in brackets.

\begin{tabular}{llll}
\hline \multicolumn{1}{c}{ Order } & \multicolumn{1}{c}{$\begin{array}{c}\text { Divergence time estimates } \\
\text { (Mya) }\end{array}$} & \multicolumn{1}{c}{ Geological era } & \multicolumn{1}{c}{ References } \\
\hline Xiphosura & $\sim 473$ & Paleozoic & Rehm et al. 2011 \\
Terebratulida & $449(518-355)$ & Paleozoic & Sperling et al. 2011 \\
Decapoda & $\sim 418.56$ & Paleozoic & Bracken et al. 2010 \\
Coleoptera & $253(268-238)$ & Paleozoic-Mesozoic & McKenna et al. 2015 \\
Scleractinia & $243(286-203)$ & Paleozoic-Mesozoic & Park et al. 2012 \\
Lingulida & $191(281-128)$ & Paleozoic-Mesozoic & Sperling et al. 2011 \\
Rodentia & $63.97(76.01-56.64)$ & Mesozoic-Cenozoic & Písano et al. 2015 \\
Sebacinales & $252(391-166)$ & Paleozoic-Mesozoic & Garnica et al. 2016 \\
Ostropales & $189(221-155)$ & Mesozoic & Prieto \& Wedin 2013 \\
Mycocaliciales & $152(226-87)$ & Mesozoic & Prieto \& Wedin 2013 \\
Boletales & $132.6(186.2-90.2)$ & Mesozoic & Sánchez-Ramírez et al. 2015 \\
Pyrenulales & $120(173-66)$ & Mesozoic & Prieto \& Wedin 2013 \\
Ustilaginales & $95(143-58)$ & Mesozoic-Cenozoic & Riess et al. 2016 \\
Chaetothyriales & $72(110-35)$ & Mesozoic-Cenozoic & Prieto \& Wedin 2013 \\
Ceramiales & $335(395-284)$ & Paleozoic & Yang et al. 2016 \\
Metzgeriales & $285(322-248)$ & Paleozoic-Mesozoic & Cooper et al. 2012 \\
Pelliales & $278(337-214)$ & Paleozoic-Mesozoic & Cooper et al. 2012 \\
Marchantiales & $196(251.9-157.4)$ & Mesozoic & Villarreal et al. 2016 \\
Sphaerocarpales & $169(234-115)$ & Mesozoic & Villarreal et al. 2016 \\
Nymphaeales & $174.42-134.79$ & Mesozoic & Bell et al.2005 \\
Magnoliales & $164.2-115$ & Mesozoic & Massoni 2014 \\
\hline
\end{tabular}

In summary, the animals grouped as orders evolved during the Paleozoic-Mesozoic (419-66 Mya), which is earlier than the fungal (Mesozoic, 252-66 Mya) and plant (Jurassic-Cretaceous, 
201-66 Mya) orders. The number of order taxa in the kingdom Animalia is higher than the kingdoms Fungi and Plantae (Ruggiero et al. 2015). The expansion into new niches by the early diverged animals might have resulted in a higher evolutionary rate with large numbers of taxa (Peterson et al. 2004).

\section{Early divergences of organisms grouped as families among the kingdoms (Table 5)}

The large number of families among the three kingdoms made it difficult to select early diverged groups. However, the representative selected divergence information related to the groups known as families in the kingdom Animalia mostly diverged during the Mesozoic (252-66 Mya, Table 5). In the kingdoms, Fungi and Plantae, the common divergences of taxa grouped as families occurred during the Middle of Mesozoic (Jurassic period) to the Cenozoic (201-2.8 Mya, Table 5).

Magallón et al. (2015) suggested that angiosperm plant families diverged continuously during the Middle of Mesozoic to the Middle of Cenozoic (134-33.9 Mya). They further suggested that an unexpected diversification and species richness occurred within the kingdom Plantae and the reason is unclear (Magallón \& Sanderson 2001, Magallón et al. 2015).

Table 5. Synopsis of early diverged groups classified as families among the kingdoms Animalia, Fungi and Plantae from recent studies. The $95 \%$ confident intervals are given in brackets.

\begin{tabular}{|c|c|c|c|}
\hline Family & $\begin{array}{c}\text { Divergence time estimates } \\
(\text { Mya) }\end{array}$ & Geological era & References \\
\hline Astartidae & $288.2(307.3-269.2)$ & Paleozoic & Gonzalez \& Giribet 2015 \\
\hline Glypheidae & $248-242$ & Mesozoic & Bracken-Grissom et al. 2014 \\
\hline Crassatellidae & $224.0(320.2-140.6)$ & Paleozoic-Mesozoic & Gonzalez \& Giribet 2015 \\
\hline Palinuridae & $221-210$ & Mesozoic & Bracken-Grissom et al. 2014 \\
\hline Machaerotidae & $206.57(215.96-197.3)$ & Mesozoic & Cryan \& Svenson 2010 \\
\hline Parastacidae & $183(185-177)$ & Mesozoic & Toon et al. 2010 \\
\hline Cynipidae & 54 & Cenozoic & Buffington et al. 2012 \\
\hline Elapidae & $31.2(35.6-26.9)$ & Cenozoic & Kelly et al. 2009 \\
\hline Otariidae & $3.85-1.68$ & Cenozoic & Fulton \& Strobeck 2010 \\
\hline Annulatascaceae & $300-200$ & Paleozoic-Mesozoic & Vijaykrishna et al. 2006 \\
\hline Parmeliaceae & $112(135.47-92.97)$ & Mesozoic & Divakar et al. 2015 \\
\hline Coccotremataceae & $111(156-70)$ & Mesozoic & Prieto \& Wedin 2013 \\
\hline Icmadophilaceae & $90(135-50)$ & Mesozoic-Cenozoic & Prieto \& Wedin 2013 \\
\hline Serpulaceae & $64(80-58)$ & Mesozoic-Cenozoic & Skrede et al. 2011 \\
\hline Ochrolechiaceae & $59(99-25)$ & Mesozoic-Cenozoic & Prieto \& Wedin 2013 \\
\hline Diplocystidiaceae & $38.22(57.15-21.76)$ & Cenozoic & Wilson et al. 2012 \\
\hline Bolletinellaceae & $36(54.48-18.7)$ & Cenozoic & Wilson et al. 2012 \\
\hline Arctomiaceae & $9(16-3)$ & Cenozoic & Prieto \& Wedin 2013 \\
\hline Marchantiaceae & $123.5(173.9-77.8)$ & Mesozoic & Villarreal et al. 2016 \\
\hline Araceae & 121.7 & Mesozoic & Nauheimer et al. 2012 \\
\hline Aytoniaceae & $111.3(152.5-80.2)$ & Mesozoic & Villarreal et al. 2016 \\
\hline Aristolochiaceae & $147.3-103.2$ & Mesozoic & Massoni 2014 \\
\hline Lauraceae & $147.2-92.2$ & Mesozoic & Massoni 2014 \\
\hline Annonaceae & $98-89$ & Mesozoic & Pirie \& Doyle 2012 \\
\hline Geraniaceae & $48(57-39)$ & Cenozoic & Sytsma et al. 2014 \\
\hline Vivianiaceae & $35(44-28)$ & Cenozoic & Sytsma et al. 2014 \\
\hline Melianthaceae & $14.4(20-10)$ & Cenozoic & Sytsma et al. 2014 \\
\hline
\end{tabular}

\section{Is ranking based on divergence times possible across the kingdoms?}

In the present study, we compare ranking of phyla, classes, orders and families across the kingdoms Animalia, Fungi and Plantae based on divergence times. In general, the animal groups classified as classes, orders and families have diverged before similar taxonomic groups in the kingdoms Fungi and Plantae. There are common divergence periods for similar taxa among the kingdoms Fungi and Animalia. Mora et al. (2011) estimated species diversity as 7.77, 0.611 and 0.298 million species within the kingdoms Animalia, Fungi and Plantae respectively. 


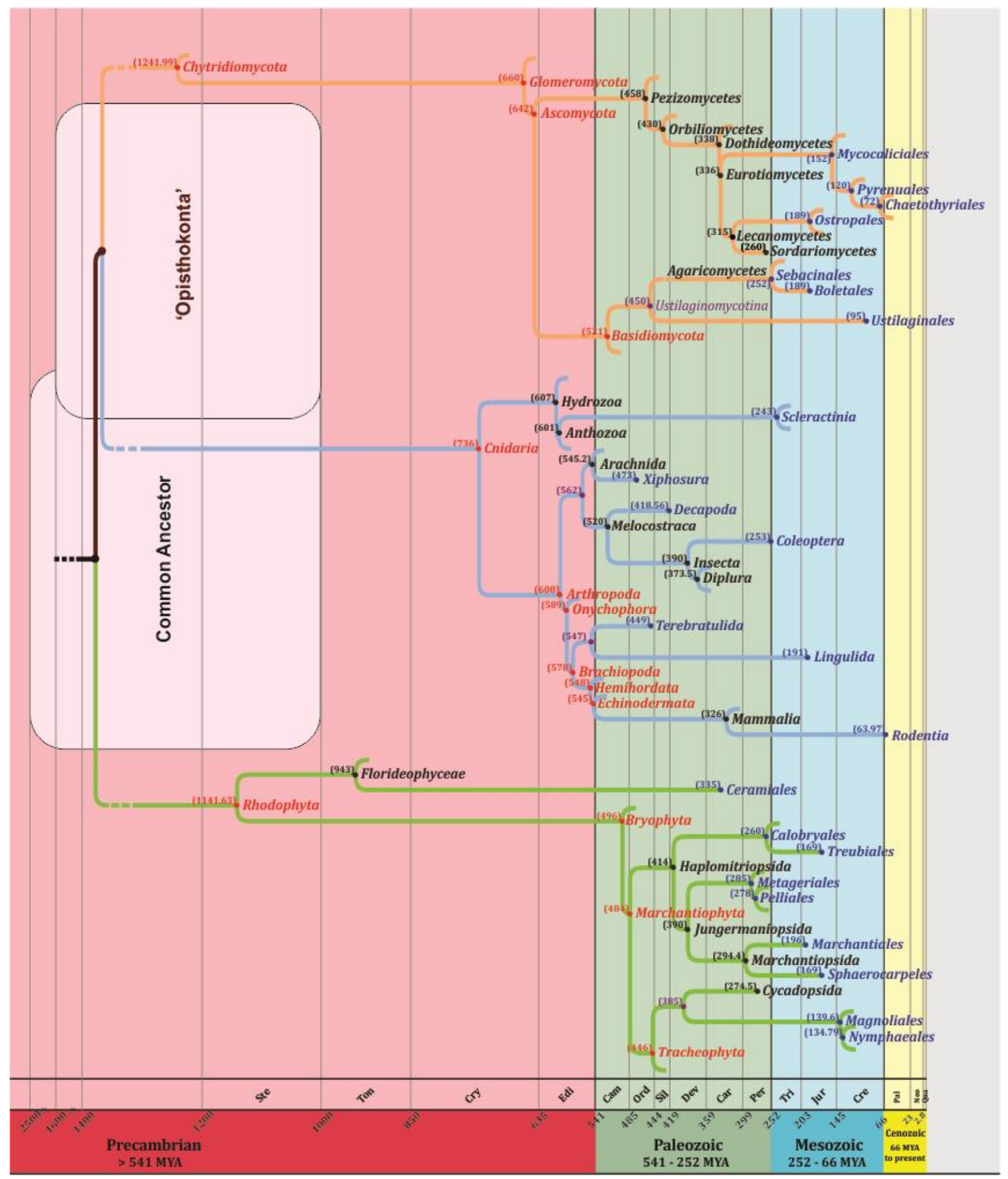

Fig. 1 - Earliest divergence times for phyla, classes and orders among the kingdoms Animalia, Fungi and Plantae. SteStenian, Ton-Tonian, Cry-Cryogenian, Edi-Ediacaran, Cam-Cambrian, Ord-Ordovician, Sil-Silurian, Dev-Devonian, Car-Carboniferous, Per-Permian, Tri-Triassic, Jur-Jurassic, Cre-Cretaceous, Pal-Paleogene, Neo-Neogene, QuaQuaternary (Walker et al. 2012). Colour bars - kingdom Animalia (blue), Fungi (orange), Plantae (green). The figure is based on divergence times, not on the ancestral relationships. The colour of the letters and dots indicate the taxa, as phylum (red), class (black), order (blue), other intermediate taxa (purple). Mean divergence times are given within brackets as Mya. The divergences of the three kingdoms from common ancestors are based on Bhattacharya et al. (2009).

Here we suggest a hypothesis that needs further consideration. Since the divergence times of the animal groups are generally older than most plant and fungi groups, it is likely that animal taxonomists have been more liberal in introducing higher taxa than plant and fungal taxonomists. 
Plant and fungal taxonomists may therefore be able to be less conservative when it comes to introducing new higher level taxa, such as classes and orders. Certainly, in the case of the fungi, were we rely on a limited number of phenotypic characters, we should start to incorporate evolutionary events to increase the resolution of our phylogenies and thus ranking of genera, families, orders, classes and phyla. Evolutionary events could be applied for future ranking of living things and it may be possible to develop a stable and natural classification system for all organisms. This however would not only be a formidable and may be an impossible task, but it may also be unnecessary to establish groupings based on evolutionary events, as a practical ranking based on phylogenies and morphology may be more desirable to the various groups of scientists.

\section{Acknowledgements}

Kevin D. Hyde thanks the Chinese Academy of Sciences, project number 2013T2S0030, for the award of Visiting Professorship for Senior International Scientists at Kunming Institute of Botany. Milan C. Samarakoon extends the gratitude to Samantha C. Karunarathna and A. Balasuriya for helpful advice.

\section{References}

Adl SM, Simpson AGB, Farmer MA, Andersen RA et al. 2005 - The new higher level classification of eukaryotes with emphasis on the taxonomy of protists. Journal of Eukaryotic Microbiology 52, 399-451.

Adl SM, Simpson AGB, Lane CE, Lukeŝ J et al. 2012 - The revised classification of Eukaryotes. Journal of Eukaryotic Microbiology 59, 429-493.

Avise JC, Johns GC. 1999 - Proposal for a standardized temporal scheme of biological classification for extant species. Proceedings of the National Academy of Sciences. USA 96, 7358-7363.

Beimforde C, Feldberg K, Nylinder S, Rikkinen J et al. 2014 - Estimating the Phanerozoic history of the Ascomycota lineages: Combining fossil and molecular data. Molecular Phylogenetics and Evolution 78, 386-398.

Bell CD, Soltis DE, Soltis PS. 2005 - The age of the Angiosperms: A molecular timescale without a clock. Evolution 59, 1245-1258.

Berbee ML, Taylor JW. 2001 - Fungal molecular evolution: gene trees and geologic time. Systematics and Evolution 7B, 229-245.

Berney C, Pawlowski J. 2006 - A molecular time-scale for eukaryote evolution recalibrated with the continuous microfossil record. Proceedings of the Royal Society of London B: Biological Sciences. 273, 1867-1872.

Bhattacharya D, Yoon HS, Hedges SB, Hackett D. 2009 - Eukaryotes (Eukaryota), Hedges SB, Kumar S (Eds.). Timetree of Life, University Press, Oxford, pp. 35-86.

Bracken HD, De Grave S, Toon A, Felder DL, Crandall KA. 2010 - Phylogenetic position, systematic status, and divergence time of the Procarididea (Crustacea: Decapoda). Zoologica Scripta 39, 198-212.

Bracken-Grissom HD, Ahyong ST, Wilkinson RD, Feldmann RM et al. 2014 - The emergence of lobsters: phylogenetic relationships, morphological evolution and divergence time comparisons of an ancient group (Decapoda: Achelata, Astacidea, Glypheidea, Polychelida). Systematic Biology 63, 457-479.

Bromham L, Penny D. 2003 - The modern molecular clock. Nature Review (Genetics) 4, 216-224.

Buffington ML, Brady SG, Morita SI, Noort SV. 2012 - Divergence estimates and early evolutionary history of Figitidae (Hymenoptera: Cynipoidea). Systematic Entomology 37, 287-304.

Burki F. 2014 - The eukaryotic tree of life from a global phylogenomic perspective. Cold Spring Harbor Perspectives in Biology 6, a016147.

Cavalier-Smith T. 2010 - Opinion piece - Protozoa, Chromista and the eukaryote root. Biological Letters, 342-345. 
Cavalier-Smith T, Chao EE, Snell EA, Berney C et al. 2014 - Multigene eukaryote phylogeny reveals the likely protozoan ancestors of Opisthokonts (animals, fungi, choanozoans) and Amoebozoa. Molecular Phylogenetics and Evolution 81, 71-85.

Clarke JT, Warnock RCM, Donoghue PCJ. 2011 - Establishing a time-scale for plant evolution. New Phytologist 192, 266-301.

Condamine FL, Nagalingum NS, Marshall CR, Morlon H. 2015 - Origin and diversification of living cycads: a cautionary tale on the impact of the branching process prior in Bayesian molecular dating. BMC Evolutionary Biology 15, 65.

Cooper ED, Henwood MJ, Brown EA. 2012 - Are the liverworts really that old? Cretaceous origins and Cenozoic diversifications in Lepidoziaceae reflect a recurrent theme in liverwort evolution. Biological Journal of the Linnean Society 107, 425-441.

Cryan JR, Svenson GJ. 2010 - Family-level relationships of the spittlebugs and froghoppers (Hemiptera: Cicadomorpha: Cercopoidea). Systematic Entomology 35, 393-415.

Divakar PK, Crespo A, Wedin M, Leavitt SD et al. 2015 - Evolution of complex symbiotic relationships in a morphologically derived family of lichen-forming fungi. New Phytologist 208, 1217-1226.

Eme L, Sharpe SC, Brown MW, Roger AJ. 2014 - On the Age of Eukaryotes: Evaluating Evidence from Fossils and Molecular Clocks. Cold Spring Harbor Perspectives in Biology 6, a016139.

Fulton TL, Strobeck C. 2010 - Multiple fossil calibrations, nuclear loci and mitochondrial genomes provide new insight into biogeography and divergence timing for true seals (Phocidae, Pinnipedia). Journal of Biogeography 37, 814-829.

Garnica S, Riess K, Schön ME, Oberwinkler F, Setaro SD. 2016 - Divergence times and phylogenetic patterns of Sebacinales, a highly diverse and widespread fungal lineage. PLoS ONE 11, e0149531.

Gonzalez VL, Giribet G. 2015 - A multilocus phylogeny of archiheterodont bivalves (Mollusca, Bivalvia, Archiheterodonta). Zoologica Scripta 44, 41-58.

Gueidan C, Ruibal C, De Hoog GS, Schneider H. 2011 - Rock-inhabiting fungi originated during periods of dry climate in the late Devonian and middle Triassic. Fungal Biology 115, 987996.

Guicking D, Lawson R, Joger U, Wink M. 2006 - Evolution and phylogeny of the genus Natrix (Serpentes: Colubridae). Biological Journal of the Linnean Society 87, 127-143.

Hedges SB, Blair JE, Venturi ML, Shoe JL. 2004 - A molecular timescale of eukaryote evolution and the rise of complex multicellular life. BMC Evolutionary Biology 4, 2.

Hongsanan S, Sánchez-Ramírez S, Crous PW, Ariyawansa HA et al. 2016 - The evolution of fungal epiphytes. Mycosphere 7, 1690-1712.

James TY, Kauff F, Schoch CL, Matheny PB et al. 2006 - Reconstructing the early evolution of Fungi using a six-gene phylogeny. Nature 443, 818-822.

Jékely G, Paps J, Nielsen C. 2015 - The phylogenetic position of ctenophores and the origin(s) of nervous systems. EvoDevo 6, 1.

Kelly CMR, Barker NP, Villet MH, Broadley DG. 2009 - Phylogeny, biogeography and classification of the snake superfamily Elapoidea: a rapid radiation in the late Eocene. Cladistics 25, 38-63.

Kemp TS. 2005 - The Origin and Evolution of Mammals. Oxford University Press Inc., New York.

Kirk PM, Cannon PF, Minter DW, Stalpers JA. 2008 - Dictionary of the fungi, $10^{\text {th }}$ (Edn). CABI, Wallingford.

Knoll AH. 2014 - Paleobiological perspectives on early eukaryotic evolution. Cold Spring Harbor Perspectives in Biology 6, a016121.

Li Y, Hyde KD, Jeewon R, Cai L, Vijaykrishna D, Zhang K. 2005 - Phylogenetics and evolution of nematode-trapping fungi (Orbiliales) estimated from nuclear and protein coding genes. Mycologia 97, 1034-1046.

Li K. 2016 - Resolving metazoan phyla divergence times during Cambrian explosion by COX I protein molecules. Journal of Biology 33, 62-67. 
Lücking R, Huhndorf S, Pfister DH, Plata ER, Lumbsch HT. 2009 - Fungi evolved right on track. Mycologia 101, 810-822.

Magallón S, Sanderson MJ. 2001 - Absolute diversification rates in angiosperm clades. Evolution $55,1762-1780$.

Magallón S, Gómez-Acevedo S, Sánchez-Reyes LL, Hernández-Hernández T. 2015 - A metacalibrated time-tree documents the early rise of flowering plant phylogenetic diversity. New Phytologist 207, 437-453.

Massoni J. 2014 - The mode and tempo of diversification in Magnoliidae. Chapter 3, PhD Thesis. Laboratoire Ecologie, Systématique, Evolution, Université Paris-Sud, CNRS UMR 8079, 91405 Orsay, France.

McKenna DD, Wild AL, Kanda K, Bellamy CL et al. 2015 - The beetle tree of life reveals that Coleoptera survived end-Permian mass extinction to diversify during the Cretaceous terrestrial revolution. Systematic Entomology 40, 835-880.

Mitchell-Olds T, Bergelson J. 2000 - Biotic interactions Genomics and coevolution; Editorial overview. Current Opinion in Plant Biology 3, 273-277.

Mora C, Tittensor DP, Adl S, Simpson AGB, Worm B. 2011 - How many species are there on earth and in the ocean?. PLoS Biology 9, e1001127.

Müller WEG. 2001 - Review: How was metazoan threshold crossed? The hypothetical Urmetazoa. Comparative Biochemistry and Physiology Part A 129, 433-460.

Müller WEG, Brümmer F, Batel R, Müller IM, Schröder HC. 2003 - Molecular biodiversity. Case study: Porifera (sponges). Naturwissenschaften 90, 103-120.

Nauheimer L, Metzler D, Renner SS. 2012 - Global history of the ancient monocot family Araceae inferred with models accounting for past continental positions and previous ranges based on fossils. New Phytologist 195, 938-950.

Nozaki H, Maruyama S, Matsuzaki M, Nakada T, Kato S, Misawa K. 2009 - Phylogenetic positions of Glaucophyta, green plants (Archaeplastida) and Haptophyta (Chromalveolata) as deduced from slowly evolving nuclear genes. Molecular Phylogenetics and Evolution 53, 872-880.

Padovan ACB, Sanson GFO, Brunstein A, Briones MRS. 2005 - Fungi Evolution Revisited: Application of the penalized likelihood method to a bayesian fungal phylogeny provides a new perspective on phylogenetic relationships and divergence dates of Ascomycota groups. Journal of Molecular Evolution 60, 726-735.

Parfrey LW, Lahr DJG, Knoll AH, Katz LA. 2011 - Estimating the timing of early eukaryotic diversification with multigene molecular clocks. Proceedings of the National Academy of Sciences 108, 13624-13629.

Park E, Hwang D, Lee J, Song J et al. 2012 - Estimation of divergence times in cnidarian evolution based on mitochondrial protein-coding genes and the fossil record. Molecular Phylogenetics and Evolution 62, 329-345.

Peterson KJ, Lyons JB, Nowak KS, Takacs CM et al. 2004 - Estimating metazoan divergence times with a molecular clock. Proceedings of the National Academy of Sciences 101, 65366541.

Philippe H, Derelle R, Lopez P, Pick K et al. 2009 - Phylogenomics revives traditional views on deep animal relationships. Current Biology 19, 706-712.

Pirie MD, Doyle JA. 2012 - Dating clades with fossils and molecules: the case of Annonaceae. Botanical Journal of the Linnean Society 169, 84-116.

Písano J, Condamine FL, Lebedev V, Bannikova A et al. 2015 - Out of Himalaya: the impact of past Asian environmental changes on the evolutionary and biogeographical history of Dipodoidea (Rodentia), Journal of Biogeography 42, 856-870.

Prieto M, Wedin M. 2013 - Dating the diversification of the major lineages of Ascomycota (Fungi). PLoS ONE 8, e65576.

Qun Y, Junye M, Xiaoyan S, Peiyun C. 2007 - Phylochronology of early metazoans: combined evidence from molecular and fossil data. Geological Journal 42, 281-295. 
Regier JC, Shultz JW, Kambic RE. 2004 - Phylogeny of Basal Hexapod Lineages and Estimates of Divergence Times, Annals of the Entomological Society of America 97, 411-419.

Rehm P, Borner J, Meusemann K, von Reumont BM et al. 2011 - Dating the arthropod tree based on large-scale transcriptome data. Molecular Phylogenetics and Evolution 61, 880-887.

Riess K, Schön ME, Lutz M, Butin H et al. 2016 - On the evolutionary history of Uleiella chilensis, a smut fungus parasite of Araucaria araucana in South America: Uleiellales ord. nov. in Ustilaginomycetes. PLoS ONE 11, e0147107.

Ruggiero MA, Gordon DP, Orrll TM, Bailly N et al. 2015 - A higher level classification of all living organisms. PLoS ONE 10, e0119248.

Sánchez-Ramírez S, Tulloss RE, Amalfi M, Moncalvo J. 2015 - Palaeotropical origins, boreotropical distribution and increased rates of diversification in a clade of edible ectomycorrhizal mushrooms (Amanita section Caesareae). Journal of Biogeography 42, 351363.

Sanders KL, Lee MSY. 2010 - Arthropod molecular divergence times and the Cambrian origin of pentastomids. Systematics and Biodiversity 8, 63-74.

Schüßler A, Schwarzotti D, Walker C. 2001 - A new fungal phylum, the Glomeromycota: phylogeny and evolution. Mycological Research 105, 1413-1421.

Skrede I, Engh IB, Binder M, Carlsen T et al. 2011 - Evolutionary history of Serpulaceae (Basidiomycota): molecular phylogeny, historical biogeography and evidence for a single transition of nutritional mode, BMC Evolutionary Biology 11, 230.

Sperling EA, Pisani D, Peterson KJ. 2011 - Molecular paleobiological insights into the origin of the Brachiopoda. Evolution and Development 13, 290-303.

Sytsma KJ, Spalink D, Berger B. 2014 - Calibrated chronograms, fossils, outgroup relationships, and root priors: re-examining the historical biogeography of Geraniales. Biological Journal of the Linnean Society 113, 29-49.

Talavera G, Lukhtanov LA, Pierce NE, Vila R. 2013 - Establishing criteria for higher-level classification using molecular data: the systematic of Polyommatus blue butterflies (Lepidoptera, Lycaenidae). Cladistics 29, 166-192.

Tanabe Y, Watanabe MM, Sugiyama J. 2005 - Evolutionary relationships among basal fungi (Chytridiomycota and Zygomycota): Insights from molecular phylogenetics - Invited review Journal of General and Applied Microbiology 51, 267-276.

Taylor JW, Berbee ML. 2006 - Dating divergences in the Fungal Tree of Life: Review and new analyses. Mycologia 98, 838-849.

Toon A, Pérez-Losada M, Schweitzer CE, Feldmann RM et al. 2010 - Gondwanan radiation of the Southern Hemisphere crayfishes (Decapoda: Parastacidae): evidence from fossils and molecules. Journal of Biogeography 37, 2275-2290.

Torruella G, Derelle R, Paps J, Lang BF et al. 2012 - Phylogenetic relationships within the opisthokonta based on phylogenomic analyses of conserved single-copy protein domains. Molecular Biology and Evolution 29, 531-544.

Vijaykrishna D, Jeewon R, Hyde KD. 2006 - Molecular taxonomy, origins and evolution of freshwater Ascomycetes. Fungal Diversity 23, 351-390.

Villarreal AJC, Crandall-Stotler BJ, Hart ML, Long DG, Forrest LL. 2016 - Divergence times and the evolution of morphological complexity in an early land plant lineage (Marchantiopsida) with a slow molecular rate. New Phytologist 209, 1734-1746.

Walker JD, Geissman JW, Bowring SA, Babcock LE. 2012 - Geologic Time Scale v. 4.0: Geological Society of America doi: 10.1130/2012.CTS004R3C.

Wang DYC, Kumar S, Hedges SB. 1999 - Divergence time estimates for the early history of animal phyla and the origin of plants, animals and fungi. Proceedings of the Royal Society London B: Biological Sciences 266, 163-171.

Wilson AW, Binder M, Hibbett DS. 2012 - Diversity and evolution of ectomycorrhizal host associations in the Sclerodermatineae (Boletales, Basidiomycota). New Phytologist 194, 1079-1095. 
Woese CR, Kandler O, Wheelis ML. 1990 - Towards a natural system of organisms: Proposal for the domains Archaea, Bacteria, and Eucarya. Proceedings of the National Academy of Science 87, 4576-4579.

Yang EC, Boo SM, Bhattacharya D, Saunders GW et al. 2016 - Divergence time estimates and the evolution of major lineages in the florideophyte red algae. Scientific Reports 6, 1-11.

Zhao R, Zhou J, Chen J, Margaritescu S, Sánchez-Ramírez S et al. 2016 - Towards standardizing taxonomic ranks using divergence times - A case study for reconstruction of the Agaricus taxonomic system. Fungal Diversity 78, 239-292

Zimmer A, Lang D, Richardt S, Frank W et al. 2007 - Dating the early evolution of plants: detection and molecular clock analyses of orthologs. Molecular Genetics and Genomics 278, 393-402. 